\title{
Malleostapedotomy with the self-fixing and articulated titanium piston
}

\author{
J. Burggraaf $^{1}$ - E. A. M. Mylanus ${ }^{1} \cdot$ R. J. E. Pennings ${ }^{1} \cdot$ Cor $^{\text {Cremers }}{ }^{1}$
}

Received: 6 March 2018 / Accepted: 12 May 2018 / Published online: 19 May 2018

(c) The Author(s) 2018

\begin{abstract}
Objective To analyze the results of malleostapedotomy performed by applying the self-fixing and articulated titanium piston according to Häusler.

Study design Retrospective case review.

Setting Tertiary referral center.

Patients and interventions This study concerns a retrospective analysis of the results of malleostapedotomy with the use of a self-fixing articulated titanium piston in 16 ears of 16 consecutively treated patients between 2005 and 2009 . The medical files were used for the acquisition of data on medical and surgical history and to obtain pre- and postoperative audiometry. Diagnosis and outcomes of mainly revision surgeries are presented and compared to the literature.

Main outcome measures Effect of (revision) malleostapedotomy by evaluating postoperative audiometry and air-bone gap closure.

Results The postoperative air-bone gap closure was $\leq 10 \mathrm{~dB}$ in $9 / 16(56 \%)$ ears and within $\leq 20 \mathrm{~dB}$ in $13 / 16(81 \%)$ ears. The mean postoperative air-bone gap was $14.3 \mathrm{~dB} \mathrm{HL}(0.5-2.0 \mathrm{kHz})$ and $17.3 \mathrm{~dB} \mathrm{HL}(0.5-4.0 \mathrm{kHz})$. Postoperatively, there was no increase in bone conduction thresholds larger than $3 \mathrm{~dB}(0.5-2.0 \mathrm{kHz})$ and postoperative dizziness was absent or very limited and transient.

Conclusions The malleostapedotomy procedure has become surgically less demanding over time by the technical improvements present in the nowadays available pistons. The design of the self-fixing and articulated titanium piston used in the present group of patients allows a safe and straight-forward malleostapedotomy procedure. Present hearing outcomes match with results presented in the literature.
\end{abstract}

Keywords Otosclerosis $\cdot$ Tympanosclerosis $\cdot$ Stapes surgery $\cdot$ Hearing loss $\cdot$ Malleostapedotomy $\cdot$ Kurz-Häusler articulated titanium piston

\section{Introduction}

The malleovestibulopexy procedure was originally a complicated surgical procedure which even in the most experienced hands has been reported to have a relatively high percentage

Electronic supplementary material The online version of this article (https://doi.org/10.1007/s00405-018-4999-z) contains supplementary material, which is available to authorized users.

Cor Cremers

cor.cremers@radboudumc.nl

1 Department of Otorhinolaryngology, Donders Institute for Brain, Cognition and Behaviour, Radboud University Medical Center, PO Box 9101, 6500 HB Nijmegen, The Netherlands of serious complications and deteriorations (1-10\%) at the level of the inner ear [1-4]. Over time, less invasive and, therefore, potentially less risky surgical procedures have been developed in case of a fixed stapes footplate and an absent or eroded incus that precludes fixation of a piston.

Following the gradual introduction of the incudostapedotomy procedure replacing the incudostapedectomy in the eighties of the previous century, the smaller opening of the footplate also became the trend in malleostapedotomy procedures $[5,6]$. The full titanium self-fixing malleus grip and articulated piston, introduced in 2004 by Häusler, renders access to the stapedotomy opening. Both the clip and the mobility at the level of the joint facilitate a more soft and gentle handling at the level of the vestibule than the 
conventional straight design piston $[6,7]$. An image of the piston is provided in Fig. 1.

The malleostapedotomy procedure has always been regarded as a most delicate and even last resort option to be applied, preferably by the most experienced hands. Surgical series in the literature, almost all quite limited in numbers, originated from mostly well-known otological centers (Table 1). The surgical outcomes for hearing and balance in the present series with the self-fixing articulated piston are presented below and compared to data from the literature on malleostapedotomy.

\section{Patients and methods}

In this retrospective study, the results obtained in 16 consecutive malleostapedotomies using the CliP® Piston MVP Häusler Design from Kurz were evaluated. The surgical procedures were performed in the period from January 2005 to July 2009. Five cases were excluded from evaluations: three cases with congenital minor ear anomalies and two cases with severe mixed hearing loss. In one of those two cases with a most severe mixed hearing loss, hearing after revision surgery gradually deteriorated to total deafness. One of the other excluded cases (case VI: 8), has been presented as part of a report on a new syndrome (Ref. [8]).

Included were eleven patients with otosclerosis, one patient with osteogenesis imperfecta and four patients with a history of chronic otitis media and tympanosclerosis. In all 16 patients, a fixed footplate was observed at previous or at revision surgery. It concerned 10 males and 6 females. Ages varied between 25 and 58 years (median age of 51 years).

In all but one of the surgical procedures, a transcanal approach with a flexible speculum holder and an aural speculum was used. In only one surgery, an endaural widening incision with canalplasty of the external auditory canal

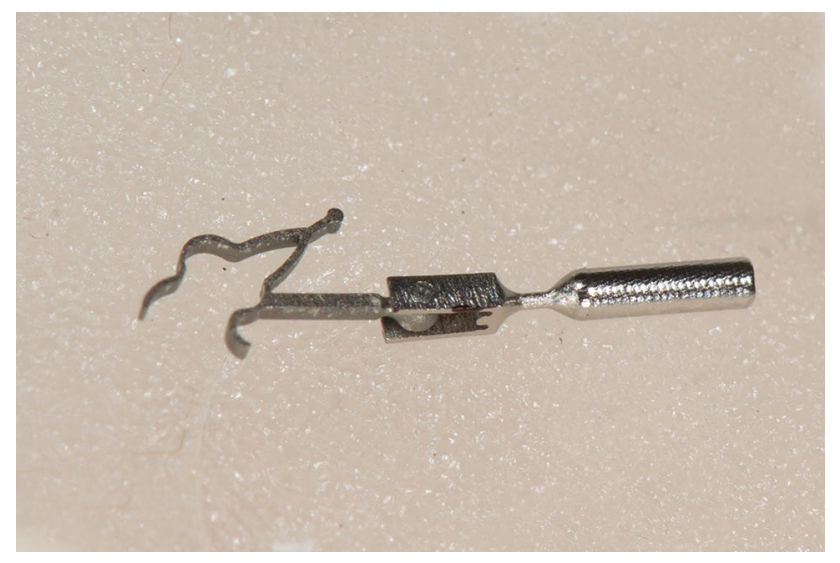

Fig. 1 The self-retaining and self-fixing titanium, malleostapedotomy clip piston according to Häusler [7] (bony widening of the ear canal) was applied. In this case, limited exposure precluded the use of the speculum holder. No cement or other material was used, either to improve fixation at the level of the malleus or to prevent extrusion of the piston on the level of the footplate. The surgical transcanal method using an aural speculum holder was well described by Häusler and Steinhart [7]. They describe the application of some fat from the ear lobe around the piston at the level of the footplate. Besides this, some bone cement was applied on the malleus to secure additional fixation of the malleus clip piston to the malleus. These extra fixations have also been reported by Häusler in figures in his review contribution on progresses made in stapes surgery [9]. Fisch [10] showed already in 1994 by figures that he secured in his malleostapedotomy procedure the fixation of the piston to the vestibule by placing connective tissue on the footplate around the piston. In addition, blood and fibrin glue were applied around to secure that fixation [10]. He named this procedure "sealing of stapedotomy opening" and has also been applied in other types of stapes surgery. In our surgical series, these extra opportunities to help to secure the fixation of the malleostapedotomy piston have not been applied.

The pre- and postoperative hearing thresholds for bone and air conduction were acquired at $0.5,1.0$ and $2.0 \mathrm{kHz}$ and for $0.5,1.0,2.0$ and $4.0 \mathrm{kHz}$, respectively. Routinely there were no data available for $3.0 \mathrm{kHz}$. The lack or presence of some direct postoperative dizziness had been noted for every case in their medical files and will be provided in addition to the hearing outcomes. The present results in terms of hearing loss were compared to a review of the literature on the outcomes of malleostapedotomy and/or malleovestibulopexy.

\section{Results}

This report includes 16 patients who have a clinical diagnosis of otosclerosis $(n=11)$, osteogenesis imperfecta $(n=1)$, or with a history of chronic otitis media and or tympanosclerosis $(n=4)$ (Table 2). There were 10 males and 6 females. Indications for a malleostapedotomy and preoperative findings are presented in supplemental table 1. In some cases, there was a combination of erosion of the long process of the incus and an epitympanic fixation of malleus/incus.

In all but one patient general anesthesia has been applied. The surgery in case 4 (Table 2) was combined with a myringoplasty of the postero-superior part of the tympanic membrane by applying autogenous cartilage as an underlay to resolve partial atelectasis involving an eroded incus. The postoperative air-bone gap was $2 \mathrm{~dB}(0.5-2.0 \mathrm{kHz})$. Autogenous cartilage was also used as an underlay graft in cases 7,8 and 13 with a history of chronic otitis media. In all 3 patients, the posterior half of the tympanic membrane was 
Table 1 Comparison of results after malleostapedotomy

\begin{tabular}{|c|c|c|c|c|c|c|c|}
\hline $\begin{array}{l}\text { Author/year (refer- } \\
\text { ence) }\end{array}$ & City of origin & No. of ears & $\begin{array}{l}\text { AB-gaps } \leq 10 \\
d B\end{array}$ & $\begin{array}{l}\text { AB-gaps } \leq 20 \\
\mathrm{~dB}\end{array}$ & $\begin{array}{l}\text { Postop- } \\
\text { erative hearing } \\
\text { improvement } \\
(\%)\end{array}$ & Type of piston & Frequencies $(\mathrm{kHz})$ \\
\hline Sheehy 1982 [1] & Los Angeles & 146 & $51 \%$ & $81 \%$ & 84 & $\begin{array}{l}\text { Stainless steel } \\
\text { wire loop pros- } \\
\text { thesis }\end{array}$ & - \\
\hline Shea 1983 [2] & Memphis & 35 & - & $(84 \%)$ & - & $\begin{array}{c}\text { Malleus all-Tef- } \\
\text { lon prosthesis }\end{array}$ & - \\
\hline $\begin{array}{l}\text { Schuknecht } 1986 \\
\text { [3] }\end{array}$ & Boston & 187 & $36 \%$ & $69.1 \%$ & - & $\begin{array}{r}\text { Schuknecht } \\
\text { prosthesis }\end{array}$ & - \\
\hline $\begin{array}{c}\text { Eberle (Fisch) } \\
1992[11]\end{array}$ & Zürich & 123 & - & - & 90 & - & - \\
\hline Tange 1996 [12] & Amsterdam & 41 & $(70 \%)$ & $(88 \%)$ & 93 & $\begin{array}{l}\text { Schuknecht } \\
\text { prosthesis }\end{array}$ & - \\
\hline $\begin{array}{l}\text { Oestreicher } \\
\text { and Häusler } \\
\text { 1998/2000/2004 } \\
{[4,13,14]}\end{array}$ & Bern & $39 / 40$ & $(40 \%)$ & $(85 \%)$ & 92 & $\begin{array}{r}\text { Schuknecht } \\
\text { prosthesis }\end{array}$ & $0.5-3.0$ \\
\hline $\begin{array}{l}\text { Fisch et al. } 2001 \\
\text { [15] }\end{array}$ & Zürich & 56 & $(18 \%)$ & $(77 \%)$ & - & $\begin{array}{l}\text { Fisch-Storz } \\
\text { titanium pros- } \\
\text { thesis }\end{array}$ & - \\
\hline $\begin{array}{l}\text { Kohan and Sorin } \\
2003[16]\end{array}$ & New York & 5 & $(60 \%)$ & $(100 \%)$ & - & $\begin{array}{l}\text { Standard } \\
\text { wire-Teflon } \\
\text { prosthesis }\end{array}$ & $0.5-3.0$ \\
\hline $\begin{array}{l}\text { Sarac et al. } 2006 \\
\text { [17] }\end{array}$ & Boston & 33 & $(44 \%)$ & $(72 \%)$ & - & $\begin{array}{l}\text { Schuknecht } \\
\text { prosthesis }\end{array}$ & - \\
\hline $\begin{array}{l}\text { Dalchow et al. } \\
2007 \text { [18] }\end{array}$ & Marburg & 6 & $(66 \%)$ & $(83 \%)$ & - & $\begin{array}{l}\text { Fisch-Storz } \\
\text { titanium pros- } \\
\text { thesis }\end{array}$ & - \\
\hline $\begin{array}{l}\text { Häusler and Stein- } \\
\text { hart } 2007 \text { [7] }\end{array}$ & Bern & 10 & - & $(100 \%)$ & - & $\begin{array}{l}\text { Kurz-Häusler } \\
\text { articulated clip } \\
\text { prosthesis }\end{array}$ & - \\
\hline $\begin{array}{l}\text { Kisilevski et al. } \\
2009 \text { [19] }\end{array}$ & Toronto & 7 (cong. ears) & $4 / 7(=57 \%)$ & $5 / 7(=71 \%)$ & - & $\begin{array}{l}\text { Causse large } \\
\text { loop Piston } \\
\text { and Cawthorne } \\
\text { prosthesis }\end{array}$ & - \\
\hline $\begin{array}{l}\text { Kisilevski et al. } \\
2009 \text { [20] }\end{array}$ & Toronto & 24 & $(33 \%)$ & $(61 \%)$ & - & $\begin{array}{l}\text { Causse large } \\
\text { loop Piston } \\
\text { and Cawthorne } \\
\text { prosthesis }\end{array}$ & - \\
\hline $\begin{array}{l}\text { Gluth et al. } 2011 \\
\text { [21] }\end{array}$ & Perth & 7 & $(43 \%)$ & $(71 \%)$ & - & $\begin{array}{l}\text { Stryker-Leib- } \\
\text { inger titanium } \\
\text { stapes piston }\end{array}$ & $0.5-3.0$ \\
\hline $\begin{array}{l}\text { Rambousek et al. } \\
2012 \text { [22] }\end{array}$ & Luzern & $60(28+32)$ & $\begin{array}{l}\text { Primary } N=28 \\
\quad(61 \%) \\
\text { Revision } N=32 \\
\quad(38 \%)\end{array}$ & $\begin{array}{l}\text { Primary } N=28 \\
\quad(100 \%) \\
\text { Revision } N=32 \\
(81 \%)\end{array}$ & - & $\begin{array}{l}\text { Fisch-Storz } \\
\text { titanium pros- } \\
\text { thesis }\end{array}$ & $\begin{array}{l}0.5-2.0 \\
0.5-3.0 \\
0.5-4.0\end{array}$ \\
\hline $\begin{array}{l}\text { Chang et al. } 2012 \\
\text { [25] }\end{array}$ & Seoul & $14(7+7)$ & $\begin{array}{l}\text { Handle }(29 \%) \\
\text { Neck malleus } \\
\quad(43 \%)\end{array}$ & $\begin{array}{l}\text { Handle }(57 \%) \\
\text { Neck malleus } \\
\quad(86 \%)\end{array}$ & - & $\begin{array}{l}\text { Platinum wire } \\
\text { piston }\end{array}$ & $0.5-3.0$ \\
\hline $\begin{array}{l}\text { Magliulo et al. } \\
2013 \text { [23] }\end{array}$ & Rome & 14 & $5(=36 \%)$ & $11(=79 \%)$ & - & $\begin{array}{l}\text { Nitinol pros- } \\
\text { thesis }\end{array}$ & - \\
\hline This series 2015 & Nijmegen & 16 & $(56 \%)$ & $(81 \%)$ & - & $\begin{array}{l}\text { Kurz-Häusler } \\
\text { articulated clip } \\
\text { prosthesis }\end{array}$ & $\begin{array}{l}0.5-2.0 \\
0.5-4.0\end{array}$ \\
\hline
\end{tabular}




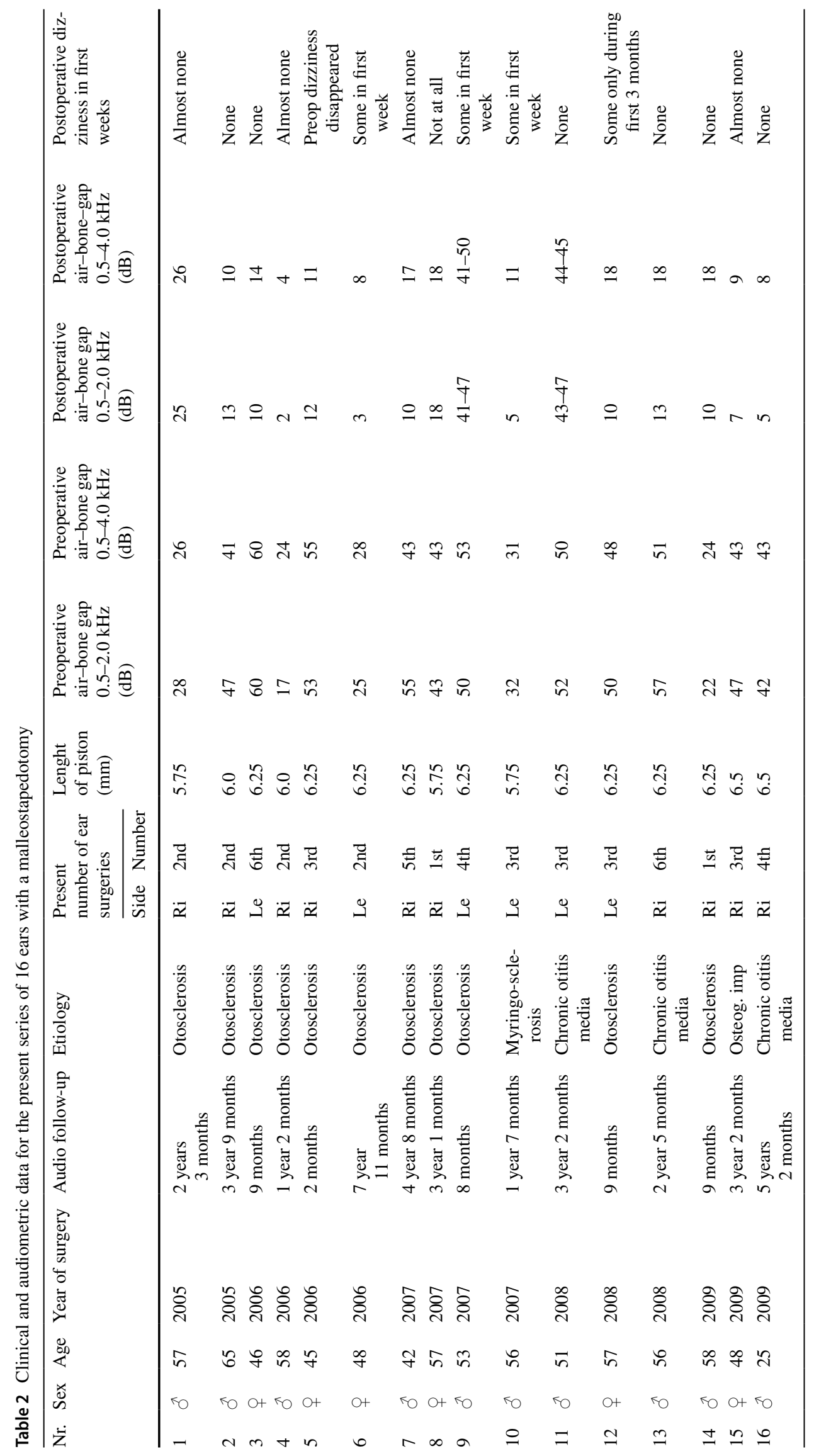


reinforced with a thin slice of autogenous cartilage glued to the medial side of the tympanic membrane to prevent atelectasis.

In this series of 16 ears of a malleostapedotomy with the Kurz-Häusler self-fixing articulated titanium prosthesis, revision surgery was performed in three patients (cases 3, 7 and 15). In all three, the revisions were successful after applying a somewhat longer piston.

The length of all the pistons applied as mentioned on its package is described for each surgery in Table 2. It varied between 5.75 and $6.5 \mathrm{~mm}$. The diameter applied was usually $0.4 \mathrm{~mm}$. In cases of previous total platinectomies the opportunity of a $0.6 \mathrm{~mm}$ diameter was used. This applied length of $5.75-6.5 \mathrm{~mm}$, usually $6.25 \mathrm{~mm}$, is longer as the usually applied length of 5.25-5.5 mm as mentioned by Häusler and Steinhart [7]. Even when applying these longer pistons, our postoperative outcomes related to the period of postoperative dizziness (Table 2) were quite good.

Many ears in the present series have had previous ear surgery. This varied between zero and five previous surgeries (Table 2). The audiometric follow-up varied between 8 weeks and 7 years and 7 months. The mean follow-up time was 3 years (Table 2). The pre- and postoperative air-bone gaps for 0.5, 1.0, 2.0 and for $0.5,1.0,2.0,4.0 \mathrm{kHz}$ are separately presented for each case in Table 2 . A postoperative air-bone gap equal or less than $10 \mathrm{~dB}$ for $0.5,1.0$ and $2.0 \mathrm{kHz}$ was found in 9/16 (56\%) cases. An air-bone gap equal or less than $20 \mathrm{~dB}$ was found in 13/16 (81\%). A comparison with the results as presented in the literature is shown in Table 1. The mean postoperative air-bone gap for this series is $14.3 \mathrm{~dB}$ for $0.5-2.0 \mathrm{kHz}$ and $17.3 \mathrm{~dB}$ for $0.5-4.0 \mathrm{kHz}$. Seven other reports on malleostapedotomy results presented also their mean postoperative air-bone gap (Table 3).

In Table 4, the postoperative air-bone gap levels are presented stratified according to the numbers of previous operations for recent series of $n=36$ ears from Boston [17] and for the present series. In the present series, even after 3,4 or 5 previous ear surgeries, equally good outcomes were found with the articulated self-fixing titanium piston.

The immediate postoperative scores for dizziness in the present series are presented in Table 2. These are in the range of the present outcomes for incudo-stapedotomy procedure.

In case 5, there were preoperative complaints of dizziness possibly related to a previously placed piston with a relatively deep position in the vestibulum as seen on CT scan. After revision surgery, the dizziness disappeared fully within days. Besides this, the air-bone gap improved from 53 to $12 \mathrm{~dB}(0.5,1.0,2.0 \mathrm{kHz})$.

However, the not-applying fat or fibrous tissue on the stapes footplate around the piston as previously propagated by Häusler [9] and Fisch [10] for revision stapes surgeries and malleostapedotomies might even have contributed to the few cases of revision surgeries in this series or showing an incomplete or even lack of success in the case nrs. 1, 9, and 11 in this series.

In cases 7 and 13, after one previous malleostapedectomy, which initially had a good outcome for the hearing, a disconnection of the piston at the level of the footplate had occurred after blowing the nose. The postoperative air-bone gap after revision surgery was $10 \mathrm{~dB}(0.5-2.0 \mathrm{kHz})$ for case $7,18 \mathrm{~dB}(0.5-2 \mathrm{kHz})$ for case 8 and $13 \mathrm{~dB}(0.5-2 \mathrm{kHz})$ for case 13 .

There has been no case of any serious deterioration of the sensorineural component postoperatively (Table 5). For the calculation of the air-bone gap, the postoperative sensorineural hearing levels could, therefore, been used.

Case 9 and case 11 are the 2 ears with postoperative air-bone gaps larger than $40 \mathrm{~dB}$. Both ears might have lost a few decibels each, but this is considered to be within the variance of such audiometric measurements.

The improvement of the postoperative sensorineural thresholds compared to the preoperative sensorineural thresholds (i.e., 'overclosure') in the remaining 14 out of 16

Table 3 Mean postoperative air-bone gap in $\mathrm{dB}$

\begin{tabular}{|c|c|c|c|c|c|c|}
\hline \multirow[t]{2}{*}{ Author (reference) } & \multirow[t]{2}{*}{ Year } & \multirow[t]{2}{*}{ Number of ears } & \multicolumn{3}{|l|}{ Frequencies } & \multirow[t]{2}{*}{ Specification } \\
\hline & & & $\begin{array}{l}0.5-2.0 \mathrm{kHz} \\
(\mathrm{dB})\end{array}$ & $0.5-3.0 \mathrm{kHz}(\mathrm{dB})$ & $\begin{array}{l}0.5-4.0 \mathrm{kHz} \\
(\mathrm{dB})\end{array}$ & \\
\hline Schuknecht and Bartley [3] & 1986 & 203 & & 14 & & \\
\hline Sarac et al. [17] & 2006 & 36 & & 14.3 & & \\
\hline Dalchow et al. [18] & 2007 & 6 & & & 13 & \\
\hline Kisilevski et al. [20] & 2009 & $24(20+4)$ & & 18.6 and 20.7 & & \\
\hline Chang et al. [25] & 2012 & $14=7+7$ & & 19.8 and 11.9 & & \\
\hline Rambousek et al. [22] & 2012 & $60=28+32$ & & 9.4 and 11.3 & & \\
\hline \multirow[t]{2}{*}{ Chang et al. [26] } & 2014 & 20 & 23.5 & & & Handle-malleostapedotomy \\
\hline & & 15 & 22.3 & & & Neck malleostapedotomy \\
\hline Present series & 2014 & 16 & 14.3 & & 17.3 & \\
\hline
\end{tabular}




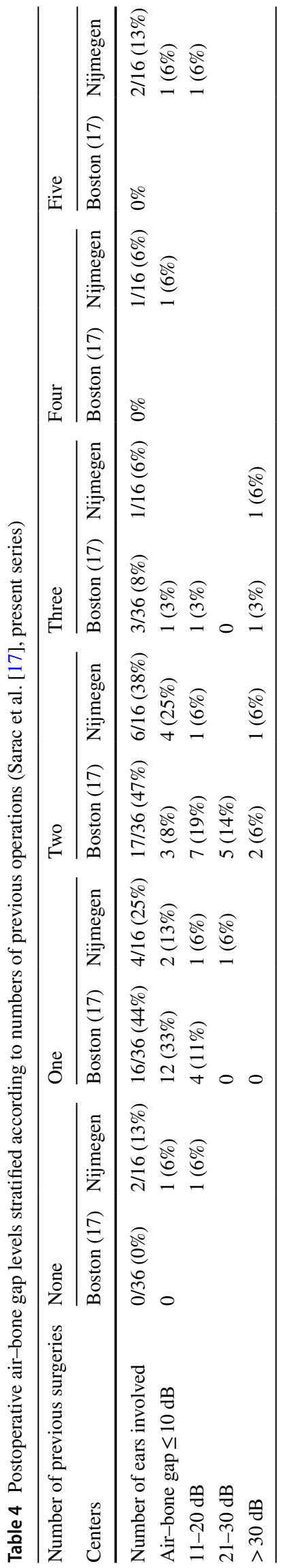

ears varied between 0 and $15.0 \mathrm{~dB}(0.5,1.0,2.0 \mathrm{kHz})$ and between 0 and $14.0 \mathrm{~dB}(0.5,1.0,2.0,4.0 \mathrm{kHz})$ (Table 5), which is indicative for overclosure. The mean improvement was $7 \mathrm{~dB}$ HL $(0.5-2.0 \mathrm{kHz})$ and $6 \mathrm{~dB} \mathrm{HL}(0.5-4.0 \mathrm{kHz})$. Häusler and Oestreicher reported a mean overclosure of $4.3 \mathrm{~dB}(0.5-3.0$ or $0.5-4.0 \mathrm{kHz})$ in 34 ears. The size of the overclosure varied from 0 to $12.5 \mathrm{~dB}$.

\section{Discussion}

The malleovestibulopexy procedures have been refined over time which has also led to a more accurate terminology, namely malleostapedotomy. The early procedures like the fat-wire piston technique with a total stapedectomy (Sheehy Ref. [1]) and the all-Teflon grip piston with an opening superiorly (Shea Ref. [2]) involved risks for the inner ear function, by rupture and eventually later adhesions of the soft tissue structures in the vestibule. This could also occur by a too deep insertion of the tip of the all-Teflon piston into the vestibule before the piston could be secured to the malleus (Shea Ref. [2]). The Schuknecht piston for a malleostapedectomy procedure required manipulation around the malleus having the tip of the piston already positioned in the vestibule (Refs. [3, 9]). Closure of the piston around the malleus was achieved by bending an extra loop of the piston around the medial aspect of the malleus. For all these procedures considerable percentages of inner ear damage have been reported $[1,3,9,11]$.

In the $80 \mathrm{~s}$, the advantages of the incudostapedotomy compared to the incudostapedectomy became well understood and, therefore, as a consequence the naming malleovestibulopexy procedure changed into malleostapedotomy [21]. As part of that procedure an endaural widening incision needed to be combined with supero-anterior widening of the bony ear canal (canalplasty) to improve the feasibility to close the titanium loop around the malleus from laterally.

Once the new self-fixing articulated titanium piston became available, fixation of the piston around the malleus has been simplified [7]. A transcanal approach, using a flexible speculum holder usually provides sufficient access to the middle ear to perform the surgical procedure adequately as has been reported by Häusler and Steinhart [7].

Table 1 shows that over time for the malleovestibulopexy and later on the malleostapedotomy an air-bone gap closure within or equal to $10 \mathrm{~dB}$ is possible for $50 \%$ of the cases and within or equal to $20 \mathrm{~dB}$ for about $80-90 \%$ of the cases. Over time, the number of ears with a malleostapedotomy reported in the literature has decreased significantly. The only exception in this is the series published by Fisch et al. [15] and Rambousek et al. [22] both applying the Fisch malleostapedotomy technique combined with a bony canalplasty. Both Swiss groups of authors have reported on larger series 
Table 5 Postoperative changes for $0.5-2.0 \mathrm{kHz}$ and for $0.5-4.0 \mathrm{kHz}$ in bone conduction threshold in $\mathrm{dB}$ after malleostapedotomies

\begin{tabular}{lllllll}
\hline Nr. & $\begin{array}{l}\text { Preoperative } \\
0.5-2.0 \mathrm{kHz} \\
(\mathrm{dB})\end{array}$ & $\begin{array}{l}\text { Preoperative } \\
0.5-4.0 \mathrm{kHz} \\
(\mathrm{dB})\end{array}$ & $\begin{array}{l}\text { Postoperative } \\
0.5-2.0 \mathrm{kHz}(\mathrm{dB})\end{array}$ & $\begin{array}{l}\text { Postoperative } \\
0.5-4.0 \mathrm{kHz}(\mathrm{dB})\end{array}$ & $\begin{array}{l}\text { Change } \\
0.5-\end{array}$ & $\begin{array}{l}\text { Change } \\
0.5-\end{array}$ \\
\hline 1 & 15 & 13.75 & 15 & & 0 & $4.0 \mathrm{kHz}$ \\
2 & 31.6 & 42.5 & 35 & 12.50 & -3.4 & -3.75 \\
3 & 35 & 38.75 & 25 & 46.25 & 10 & 8.75 \\
4 & 38.5 & 41.25 & 25 & 30 & 13.5 & 13.5 \\
5 & 38.5 & 38.75 & 23.3 & 28.75 & 15.2 & 13.75 \\
6 & 51.6 & 52.5 & 43.4 & 25 & 8.3 & 10 \\
7 & 25 & 30 & 20 & 42.5 & 5 & 2.5 \\
8 & 41.6 & 36.25 & 28.3 & 27.5 & 13.3 & 11.25 \\
9 & 15 & 12.5 & 13.3 & 25 & 1.7 & -5.5 \\
10 & 43.3 & 47.5 & 31.6 & 17.5 & 11.7 & 6.25 \\
11 & 46.6 & 48.75 & 50 & 41.25 & -3.33 & -2.25 \\
12 & 13.3 & 18.75 & 10 & 51.25 & 3.3 & 2.5 \\
13 & 31.6 & 35 & 25 & 16.25 & 6.6 & 7.5 \\
14 & 36.6 & 45 & 36.6 & 27.5 & 0 & 0 \\
15 & 65 & 66.25 & 53.3 & 45 & 11.7 & 10 \\
16 & 10 & 8.75 & 8.4 & 56.25 & 1.6 & 2.5 \\
\hline
\end{tabular}

possibly because both prefer the malleostapedotomy above the incudostapedotomy procedure in case they have any doubt about the optimal mobility of the malleus incus complex. Therefore, the malleostapedectomy procedure is frequently a primary surgical intervention. Rambousek et al. [22] presented even better hearing outcomes for the group with primary surgery compared to the group with revision surgery.

The results of series presented here fits into the range of results reported in the literature. Over time, the risks for inner ear functions as hearing and balance have decreased so much that these fit into the range known for the incudostapedotomy.

Table 2 for the series reported here shows that the postoperative dizziness noted was none or only very limited for a short while. Even applying relatively longer pistons our postoperative outcomes in terms of postoperative dizziness (Table 2) were quite good.

No remarkable deterioration of the sensorineural hearing level was noted in the series presented here (Table 5). Häusler and Oestreicher [4] also published in detail outcomes for their malleostapedectomy series using the same prothesis. The preoperative thresholds improved in all their successfully operated ears (Table 3).Over time, the risks for inner ear function seem to be decreased considerably and have become comparable to incudostapedotomy.

Our present series shows good results compatible with the standard outcomes as reported earlier in the literature. Explicit are the good outcomes for the vestibular system postoperatively (Table 2 ). The great advantage of applying the new articulated self-fixing titanium malleostapedotomy piston is that even with a limited transcanal approach, fixation of the piston by its self-fixing mechanism can be realized readily without introduction of the tip of the piston first. As a result of the design with the articulation, the final introduction of the piston may follow as a wellcontrolled step. Another advantage is that the medial end of the piston will finally have a $90^{\circ}$ position to the stapedotomy opening. Especially in ears where the anatomical position (axis of the malleus) related to the oval window niche is quite anteriorly, this articulation helps to bridge that distance and facilitates a position of the stapedotomy opening in the most preferred place at the footplate just a bit inferior or posterior of the center.

This adjustable length of the piston facilitates the application of a somewhat longer piston as sometimes is needed during malleostapedotomy compared to the incudostapedotomy procedure. Having a $90^{\circ}$ direct access by the articulation of the piston to the stapedotomy opening in the middle of the footplate and being able to clip the piston first to the malleus before the medial part of the piston is brought into the vestibule will have even especially contributed to that good outcome.

Results like presented in this series might even improve in the next future by applying some additional fat or fibrous tissue with some fibrin glue around the piston on the footplate to help to decrease the risk of a dislocation of the piston at the stapedotomy level. Another surgical possibility is the application of bone cement to the eroded long process of the incus to restore its integrity and make it suitable for a regular stapes piston as was described by Van Rompaey et al. 
In conclusion, the outcomes of this series with the new self-fixing articulated titanium piston for the malleostapedotomy procedure are comparable with the surgical outcomes known in the literature for this procedure (Table 1). The simplification of the malleostapedotomy procedure facilitated by the new design of this piston provides a strong argument to expect that this latest step in the development of malleostapedotomy procedures will get a worldwide acceptance.

\section{Compliance with ethical standards}

Conflict of interest All authors disclose no conflict of interest.

Open Access This article is distributed under the terms of the Creative Commons Attribution 4.0 International License (http://creativeco mmons.org/licenses/by/4.0/), which permits unrestricted use, distribution, and reproduction in any medium, provided you give appropriate credit to the original author(s) and the source, provide a link to the Creative Commons license, and indicate if changes were made.

\section{References}

1. Sheehy JL (1982) Stapedectomy: incus bypass procedures. A report of 203 operations. Laryngoscope 92:258-262

2. Shea JJ (1983) Malleus teflon piston prosthesis. Laryngoscope 93:989-991

3. Schuknecht HF, Bartley ML (1986) Malleus grip prosthesis. Ann Otol Rhinol Laryngol 95:531-534

4. Häusler R, Oestreicher E (2000) Malleus-grip stapedectomy. Surgical technique and results. In: Rosowski JJ, Merchant S (eds) Function of mechanics of normal, diseased and reconstructed middle ears. Kugler Publications, The Hague, pp 261-270

5. Cremers CWRJ, Beusen JMH, Huygen PLM (1991) Hearing gain after stapedotomy, partial platinectomy or total stapedectomy for otosclerosis. Ann Otol Rhinol Laryngol 100:959-961

6. Garretsen AJTM, Cremers CWRJ (1991) Stapes surgery in osteogenesis imperfecta. Analysis of postoperative hearing loss. Ann Otol Rhinol Laryngol 100:120-130

7. Häusler R, Steinhart U(2007) A new self-fixing and articulated malleus grip stapedectomy prosthesis. Adv Otorhinolaryngol 65:197-201

8. Thomeer HG, Morava E, Verbist M, Cremers CW (2013) Otological aspects and surgical outcome in a consanguineous family with a novel ANKH gene mutation. Int J Ped Otorhinolaryngol 77(7):1152-1157

9. Häusler R(2000) Fortschritte in der Stapeschirurgie. LaryngRhino-Otol 79 supp 2:95-139
10. Fisch U (1994) Tympanoplasty, mastoidectomy and stapes surgery. Georg Thieme, Stuttgart, p 292

11. Eberle L (1994) Indikation und Resultate der Incus ersatz stapedotomie bei fixierter und mobieler Fussplatte.Aktuelle Probleme der Otorhinolaryngologie. Verlag Hans Huber, Bern, pp 91-98

12. Tange RA (1996) Ossicular reconstruction in cases absent or inadequate incus, congenital malformation of the middle ear and epitympanic fixation of the incus and malleus. ORL 58:143-146

13. Oestreicher E, Häusler R (1998) Technik und Resultaten der Hammergriffstapedektomie. Otorhinolaryngol Nova 8:223-229

14. Häusler R (2004) Advances in stapes surgery. Chapter 5 pg. 71-93. In: Jahnke K (ed) Middle ear surgery. Recent advances and future directions. Thieme Stuttgart, New York

15. Fisch U, Acar GO, Huber AM (2001) Malleostapedotomy in revision surgery for otosclerosis. Otol Neurotol 22:776-785

16. Kohan D, Sorin A (2003) Revision stapes surgery: the malleus to oval window wire-piston technique. Laryngoscope 113:1520-1524

17. Sarac S, McKenna MJ, Mikulec AA, Rauch SD, Nadol JB, Merchant SN (2006) Results after revision stapedectomy with malleus grip prosthesis. Ann Otol Rhinol Laryngol 115:317-322

18. Dalchow CV, Dünne AA, Sesterhem A, Teymoortash A, Werner JA (2007) Malleostapedotomy-the Marburg experience. Adv Otorhinolaryngol 65:215-221

19. Kisilevski V, Bailie NA, Dutt SN, Halik JJ (2009) Hearing results of stapedotomy and malleovestibulopexy in congenital hearing loss. Int J Pediatr Otorhinolaryngol 73:1712-1717

20. Kisilevski V, Bailie NA, Dutt SN, Safar A, Halik JJ (2009) The Markham-Stoufville Hospital experience with malleovestibulopexy. J Otolaryngol Head Neck Surg 38:595-602

21. Gluth MB, Motakef S, Friedland PL, Atlas MD (2011) Incus replacement malleostapedotomy in quiescent chronic otitis media with a mobile stapes footplate: an alternative to TORP in select cases. Otol Neurotol 32:242-245

22. Rambousek A, Schlegel CH, Linder TE (2012) From incus bypass to malleostapedectomy: technical improvements and results. J Laryngol Otol 126:995-1002

23. Magliulo G, Appiani MC, Colicchio MG, Covelli E, Massimo R (2013) Malleostapedotomy with a self-crimping superelastic nitinol prosthesis. Laryngoscope 123:492-495

24. Dalchow CV, Dünne AA, Sesterhenn A, Teymoortasch A, Werner JA (2007) Malleostapedotomy-the Marburg experience. Adv Otorhinolaryngol (Basel) 65:215-221

25. Chang MY, Jang JH, Song J-J, Han K-H, Lee JH, Oh SH, Chang SO (2012) Malleus neck-anchoring malleostapedotomy preliminary results. Otol Neurotol 33:1477-1481

26. Chang SD, Park MN, Oh SH, Kim CS (2014) Malleostapedotomy: why the prosthesis is crimped at neck of malleus? Book of abstracts nr. A-0030 3rd Int Symp on Otosclerosis and stapes surgery, April 24-26, 2014. Siofok, Hungary 